\section{Richtlinien gegen Übelkeit und Erbrechen}

In jahrzehntelanger Forschungsarbeit wurden Strategien erarbeitet, wie sich Nausea und Vomitus infolge einer Chemotherapie verhindern lassen. Wie effektiv können die daraus erstellten Richtlinien Krebs-Patienten vor diesen belastenden Nebenwirkungen schützen, wenn sie konsequent angewendet werden?

$\mathrm{R}$ ichtlinien für eine antiemetische Therapie zur Rermeidung von Nausea und Vomitus infolge Chemotherapie sind inzwischen weithin etabliert. Angewendet aber werden sie in der Praxis nicht durchgehend. Wie gut würde es Krebspatienten gehen, wenn die antiemetische Therapie auch richtliniengerecht eingesetzt würde? Der Frage ging eine multizentrische, internationale Arbeitsgruppe nach.

In die prospektive Beobachtungsstudie wurden chemotherapienaive Erwachsene aufgenommen, die gerade eine hoch oder moderat emetogene Chemotherapie (HEC oder MEC) gegen eine Krebserkrankung begannen. Die Patienten schrieben in Tagebücher, wie es ihnen während der Chemotherapie erging. Als primärer Endpunkt galt eine vollständige Remission (keine Emesis und kein Einsatz einer Rescue-Therapie binnen 120 Stunden nach Zyklus 1).

Während des Zyklus 1 ( $\mathrm{n}=991$ Teilnehmer) erhielten $55 \%$ der Patienten eine richtlinienkonforme Emesis-Prophylaxe während der akuten Phase; während der verzögerten Phase waren es noch $46 \%$, für die gesamte Periode waren es $29 \%$. Eine vollständige Remission wurde bei 172/287 Patienten $(59,9 \%)$ in der richtlinienkonformen Gruppe, aber nur bei 357/704 Patienten (50,7\%) in der nicht richtlinienkonformen Kohorte festgestellt ( $\mathrm{p}=$ 0,008 ). Die Odds Ratio betrug damit 1,43 zugunsten der Patienten, die eine richtlinienkonforme Therapie erhielten.

Fazit: Sowohl in der akuten als auch in der verzögerten Phase und der Gesamtphase einer Chemotherapie zeigt sich ein signifikanter Nutzen der richtlinienbasierten antiemetischen Therapie. Diese Ergebnisse unterstreichen, wie wichtig es ist, Forschungsergebnisse „from bench to bedside“ $\mathrm{zu}$ bringen, damit Patienten in der Klinik tatsächlich davon profitieren können.

Christina Berndt

Aapro $M$ et al. The effect of guideline-consistent antiemetic therapy on chemotherapy-induced nausea and vomiting (CINV): The Pan European Emesis Registry (PEER). Ann Oncol. 2012;23(8):1986-92.

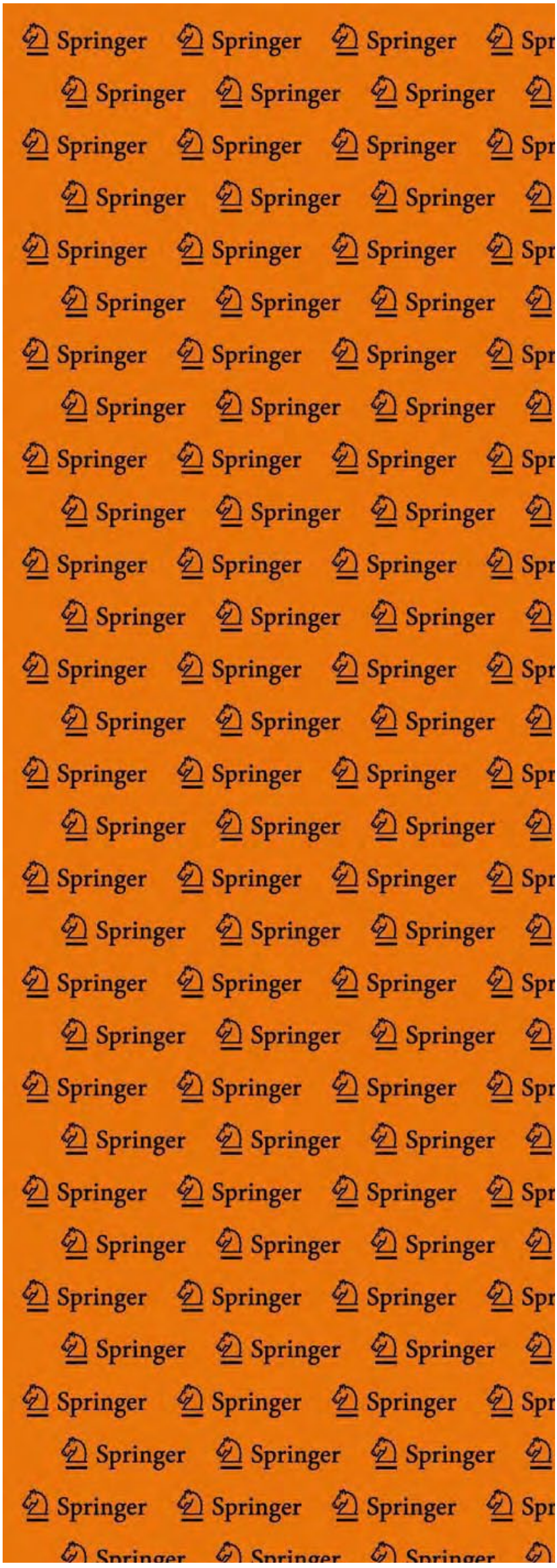

